\title{
El principio de congruencia en el proceso penal ${ }^{1}$
}

\section{The consistency principle in criminal procedure}

Fecha de Recepción: 8 de marzo de 2016

Fecha de Aprobación: 7 de junio de 2016

\section{RESUMEN}

El presente documento obedece a una reflexión personal del autor, mediante la cual se aborda desde su propia experiencia, conocimientos y, en especial, desde la percepción que tiene del asunto en contexto.

La importancia de centrar este escrito en el denominado principio de congruencia radica en el interés de explicar jurídicamente la actuación del juez, desde el momento en que a una persona se le acusa de un acto delictivo; punto de partida, para comenzar a ejercer el derecho de defensa y contradicción, para lograr la denominada igualdad procesal, pero dejando siempre presente que desde el inicio la defensa debe estar orientada en controvertir la acusación inicialmente creada y como ese marco debería ser inamovible en cualquier sistema judicial para no generar espacios de desventaja en un proceso penal.

1 Artículo derivado del proyecto de investigación "La transformación del concepto de víctima en el marco de la Justicia Transicional” proyecto adelantado para optar el título de mágister en Derecho Penal en la Universidad Militar Nueva Granada

2 Abogado Universidad Libre, especialista en Derecho Penal y Criminología, magister en Derecho Penal de la Universidad Libre, exsecretario de la Sala Penal del Tribunal Superior de Quibdó-Chocó, asesor y litigante, docente Universidad Militar Nueva Granada. Correo electrónico: ivan.valderrama@unimilitar.edu.co. 
Palabras clave: proceso penal, principio de congruencia, imputado, actuación procesal, juez, igualdad procesal.

\section{Abstract:}

The present document reflects the author's personal reflection whereby, approached from his own experience, knowledge and especially from the perception of the particular subject in context.

The importance of this paper focus on the so-called congruence principle. Focus on the interest of legally explain the actions of the judge, from the time a person is accused of a crime. As a starting point for beginning the exercise of the right defense and contradiction, and thus, achieve the procedural equality. But, having always present, that since the beginning the defense must be oriented to contest the initial accusation created and how that framework should be immovable over any judicial system, in order to avoid areas of disadvantage in criminal proceedings.

Keywords: criminal proceedings, matching principle, imputed, procedural act, judge, procedural equality.

\section{INTRODUCCIÓN}

Desde tiempos inmemoriales se ha establecido como necesidad la tarea de administrar justicia, la misma para lograr el equilibrio en las relaciones sociales de todos los administrados. Esa tarea, quizá, sea una de las más difíciles que puede tener un ser humano dentro de todas las demás que pueda desarrollar en una comunidad; por supuesto, la evolución de dicho proceder ha sido enmarcada en varias ramas del derecho, pero con mayor relevancia en lo que hoy se conoce como Derecho Penal. Se debe entender esta acepción como una herramienta de naturaleza coercitiva que posee el Estado con el fin, en principio, de prevenir conductas de naturaleza reprochable. Seguido a ello imponer sanciones, garantizar reparaciones y finalmente ofrecer a los administrados un respuesta pronta y oportuna a situaciones en concreto, todo 
esto por supuesto sin llegar a los excesos o la precariedad en su materialización, lo que implica un profundo respeto por los principios y garantías fundamentales.

Ahora bien, el modelo de constitución del Estado es la base fundamental para adoptar en las legislaciones internas los principios o garantías que deban regir la actuación procesal penal. Es por ello que, con base en el tipo adoptado por el Estado colombiano, derivado de la concepción antropocéntrica donde el hombre es el pilar fundamental del mismo, o denominado social y de derecho, el proceso penal necesariamente se ha tenido que adecuar a dichos postulados, los cuales están enmarcados en normas de rango constitucional y legal y que tienen como fin proveer una eficiente y eficaz actuación procedimental penal, siempre revestida de un plus de extensas garantías en favor del individuo cuando sea sujeto pasivo de una persecución penal.

Dentro de las garantías que cobijan al procesado, se establece el principio de congruencia como una de ellas, el cual al abordarlo jurídicamente origina el problema de investigación que se desarrolla en el presente artículo. Dicho problema consiste en cómo lograr de manera inseparable la congruencia entre la acusación y la posterior condena, en cualquier proceso de naturaleza penal; a su vez se analizará que incidencias tiene en el procedimiento, los modelos jurídicos e históricos han hablado de la congruencia como pilar central del procedimiento penal y, finalmente, cómo Colombia ha adoptado un criterio de congruencia adecuado a las necesidades de la legislación positiva nacional.

Lo expuesto permite esgrimir el siguiente problema de investigación: ¿Existen en el Derecho Penal unos lineamientos taxativos que permitan la aplicación del principio de congruencia, sin ir en detrimento del procesado? Para desatar esa cuestión se adoptará un modelo de investigación de tipo jurídico exploratorio, pues se abordará históricamente el principio de congruencia, tomando como referencia las teorías jurídicas documentadas más trascendentales y finalmente se encasillará el modelo nacional en alguno de ellos, con las características propias que el Derecho colombiano le pudo adicionar, sumado a las conclusiones personales del autor desde una perspectiva crítica constructiva.

El método a utilizar es el documental, que permite la consulta y depuración del material pertinente para dar respuesta a la pregunta de investigación. A su vez los 
objetivos serán identificar que es la congruencia, analizar su evolución en el sistema procesal penal nacional y finalmente elaborar una crítica al manejo actual del mismo.

Lo expuesto permite proponer el siguiente objetivo general que señala: determinar los lineamientos y aplicación del principio de congruencia en el proceso penal. Así, en materia penal en palabras de la Corte Suprema de Justicia en su Sala de Casación Penal, el principio de la congruencia puede entenderse como:

"La concordancia entre la sentencia y acusación, cualquiera sea el acto en el cual se halle contenida ésta (resolución, formulación de cargos para sentencia anticipada, o variación de la calificación provisional durante el juzgamiento), constituye, de un lado, base esencial del debido proceso, en cuanto se erige en el marco conceptual, fáctico y jurídico, de la pretensión punitiva del Estado y, de otro, garantía del derecho a la defensa del procesado, en cuanto que a partir de ella puede desplegar los mecanismo de oposición que considere pertinentes y porque, además, sabe de antemano que, en el peor de los casos, no sufrirá una condena por aspectos que no hayan sido contemplados alli’" (Corte Suprema de Justicia Sala de Casacion Penal, 2014)

De ahí la importancia del tema planteado y cómo la variación de la calificación jurídica después de la acusación puede llegar a generar desventajas a la defensa. Esta temática no ha sido pacifica, partiendo de la falta de uniformidad en su regulación legal, pasando por el desarrollo jurisprudencial que marca la pauta para lograr una adecuada aplicación tanto de la congruencia, como de la variación de la calificación jurídica. Por ello, podría pensarse que la existencia de regulación legal es insuficiente para referirse a un principio de derecho penal tan importante.

En este sentido, y teniendo en cuenta que en la teoría general del proceso, no existe proceso sin pretensión, más aún en el campo del derecho penal lo que busca el ente de persecución es una sentencia de tipo condenatorio. Por ende, será inminente que aquella deba guardar relación con la pretensión inicial, en dicho proceder se trata de conservar una concordancia, coherencia y congruencia entre la petición inicial y la decisión. Por ello, desde esa orbita se deberán garantizar los principios como el derecho a la defensa y debido proceso. 


\section{ANTECEDENTES}

La fundamentación del principio de congruencia se remonta a la Grecia antigua en manos de la lógica Aristotélica que establecía que "la mente reproduce solo la realidad, la existencia de las cosas tal y como son" (Grambra y Oriol, 2008, pág. 329). Significa que Aristóteles hacía referencia a una ciencia objetiva desglosando los conceptos en predicables y predicamentos, como parte fundamental del saber ontológico. En este sentido, la lógica analiza juicios y formas de razonamiento y la forma de expresar resultados es el razonamiento categórico; es decir, se consolida como un instrumento para la enseńanza en orden al conocimiento de la verdad.

"En este sentido, en la teoría silogística del Derecho, el juicio era comprendido como una estructura cerrada en el cual la premisa mayor era la norma aplicable al caso y al referirse a la premisa menor era esta entendida como el hecho relevante, y la conclusión era la decisión que aplica la norma al caso concreto, por eso se dice que desde la filosofía aristotélica, la decisión del juez y su razonamiento debe recorrer un determinado camino para alcanzar la respuesta adecuada al caso" (Artiga, 2013, pág. 29).

En el Derecho Romano, el principio de congruencia tiene sus antecedentes desde el sistema formulario hasta el extraordinario. En Justiniano, se entendía desde las Institutas en las que se encontraba que "si el demandante, en la intentio, comprendía más de lo que era debido, caía la causa, es decir, perdía la cosa y era difícil que el pretor se la restituyera a menos que fuera menor de veintiocho años" (Martínez, 2012, pág. 23).

En Roma, el juez solía utilizar una fórmula magistral: "si la intentio del actor no está justificada, debía absolver al demandado si paret condemna; si nono paret, absolve" (D’onofrio, 1945, pág. 90). Entonces, se afirmaba como consecuencia que el juez estaba obligado a condenar al demandado, de lo contrario debía absolverlo. Por su parte, la intentio enunciaba la razón que el actor hacía valer en un juicio resultando fundamental, "en ella se contenía la apreciación unilateral que hacia el actor del punto litigioso; apreciación que sería objeto de la declaración del juez que podía ser aprobada o rechazada por este" (Martínez, 2012, pág. 24). 
Lo opuesto era la condemnatio, que hacía referencia a la condena o la absolución. Estas condenas, "dependían de otras premisas, puestas como condiciones negativas y que servían, a menudo, de defensa del demandado” (Martínez, 2012, p. 24).

De otra parte, de forma discrecional de la intentio se encontraba la postura del demandado que bien podía consistir en la no aceptación de las razones expuestas por el actor, o en contraposición prescindiendo de reconocer o negar el fundamento de la acción, buscando impedir los efectos de la condena. Así, la acción del demandado se consolida como el postulado necesario para el desarrollo de los poderes del juez, significa que era la forma de iniciar el proceso. De no existir tal acción, se le imputaba al demandado las consecuencias que se desprendían de la falta de defensa.

"En la época de Justiniano el proceso era precedido de los libellus conventionis et contradictionis, y se iniciaba con la exposición que el actor hacia ante el juez de los hechos - narratio - y con las objeciones que eran las contradictio que efectuaba el demandado; seguía el jusjurandum calumniae, juramento por el que las partes declaraban, el actor, haber intentado su acción y el demandado resistir, con la plena convicción de tener derecho. Después del desfile de las pruebas, el juez redactaba las sentencias por escrito y la leía en voz alta, en presencia de sus subalternos y de las partes. La sentencia podía ser de absolución o de condena” (pág. 25).

Contribuyen a la historia del principio de congruencia los avances ofrecidos por la legislación española. "El artículo 61 de la Ley de Enjuiciamiento Civil Española de 1855 estableció: las sentencias deben ser claras y precisas declarando, absolviendo o condenando al demandado" (D’ onofrio, 1945, pág. 91). En consonancia, con lo expuesto por el artículo se hace alusión a lo señalado por Manresa y Navarro (1905), quienes siguiendo los lineamientos normativos establecían que las "sentencias deben ser congruentes con las demandas y con las demás pretensiones deducidas oportunamente en el litigio" (p. 98).

Contribuye, además de lo señalado, lo establecido en el Fuero Real de España, que mostraba que las sentencias deben darse sobre aquello que fue la demanda y no sobre algo diferente, de modo que, desde el inicio del Derecho común español puntualmente en la partida III, Titulo XXI, Ley 16 se señalan las siguientes razo- 
nes de congruencia, la que consiste en conceder cosa distinta de lo pedido - extra petitum -, la que denota - ultra petitum - y la que se muestra en la omisión de pronunciamiento.

Los antecedentes del principio de congruencia desde el punto de vista civilista resultan de gran importancia, toda vez, que era la forma como se le daba el alcance a los procesos, siendo la congruencia la vía por la cual se reclamaba la necesaria identidad de los actos procesales.

La congruencia a partir del Derecho Procesal privado tiene varias razones que abrevan en la reflexión y en los fundamentos históricos. Por una parte, no se pierde de vista que muchos fueron los delitos tramitados por la vía del procedimiento civil. Así que muchas de las causas que posteriormente conocerían la ruta procesal penal, ya habían transitado la civil, lo cual reclama atenderlo dentro de su escenario natural.

Por otra parte, es preciso destacar que más que una desatención del proceso penal en las fuentes, dicha desatención parece provenir más de los estudiosos. Es decir, no es que se trate de un menor desarrollo del proceso penal, sino de una falta de estudios que relieven ese desarrollo. Pero tampoco se puede confirmar ni afirmar que el procedimiento civil en algo al menos haya pautado el camino del proceso penal.

Por ello, se hizo alusión al procedimiento civil, el cual otorga la información pertinente, para lograr comprender el desarrollo de la congruencia en materia penal, que emanada del proceso civil, no solamente da cuenta de su existencia efectiva, sino de las características particulares que, a no dudarlo, contribuyó a la congruencia actual del proceso penal contemporáneo.

Aclarado lo anterior, es necesario establecer que no existen expresamente las fuentes relacionadas con el proceso penal, quizá porque estas fueron emergiendo de la práctica civil. Así, entrando en materia, en Roma se conoció tres esquemas de procedimiento penal. En primer lugar, la llamada provocatio ad populum, posteriormente las quaestiones perpetuae $\mathrm{y}$, finalmente la cognitio extra ordinem.

Provocatio ad populum: "institución de Derecho Público romano consistente en el derecho que tenían los ciudadanos de apelar al Pueblo reunido en comicios contra 
las sentencias de los Magistrados que considerasen abusivas, injustas o contrarias al Derecho de Roma, especialmente las que imponían una pena capital” (Trillo, 2008, pág. 25).

Bajo este esquema el magistrado adoptaba una determinación que la asamblea podía aprobar o desaprobar.

"La provocatio ad populum requiere de una condena previa de un Magistrado y nace como un llamamiento, una apelación a la asamblea del Pueblo romano, que debía reunirse bajo la forma de los comicios centuriados -maximum comitiatum-al menos cuando se tratase de la imposición de una pena capital” (pág. 27).

Lo cierto es que bajo este esquema el magistrado adoptaba una determinación que la Asamblea podía aprobar o desaprobar, se podría afirmar que este esquema tenía un tinte inquisitorial, aunque tal condición no es del todo clara debido a que el magistrado indagaba y adoptaba una decisión, finalmente quien fungía como una especie de juez superior eran los comitia - asamblea -, inicialmente curiados posteriormente centuriados. Así, el magistrado debía vencer al acusado ante los comicios, mediante pruebas que este podía desvirtuar ante los mismos comicios, conforme a una reglas preestablecidas, debería ser más que justa razón para concluir en que hay una mayor proximidad al esquema acusatorio que al inquisitorial.

Se concluye de este esquema que la verdad procesal no era la que por cognitio quisiera imponer el magistrado, sino aquella que al constituirse procesalmente en mejores fundamentos resultaba acogida por el juez. Al fin y al cabo, prosperaba la sentencia del magistrado solo a condición de haber demostrado sus presupuestos, los cuales bien podían ser desvirtuados por el procesado.

Si a los comicios les era presentada la causa en los términos propuestos por el magistrado, se tienen razones para concluir que no por un simple criterio de ordenación procesal, era irremediable operar una relación de congruencia con la decisión final. Pero ello no surge de una cierta concepción jurídica - procesal, sino del curso inevitable de los hechos: 
Pugliese (citado en Moya, 2012) señalaba que los comicios no sabían de derecho, ni tenían el tiempo bastante para acudir con un jurista para encauzar su decisión. Si era así, cuanto podían decidir se extrapola en dos opciones fundamentales e incompatibles: que había cierto en la decisión del magistrado o por el contrario se había equivocado. Por consiguiente, los comicios podían reafirmar la decisión del magistrado o por el contrario cambiar su sentido, pero que se sepa no le era atribuido proferir una sentencia observando alguna tercera vía (p. 46).

- Questiones Perpetuae: Para la primera época de la República la existencia del Derecho Penal era dudosa debido al amplio arbitrio del Magistrado, tanto para calificar los hechos como para la individualización de la pena. Así, según Mommsem (citado en Trillo, 2008) estima que:

"El fundamento del Derecho Penal de la República residía en la coercitio, cuyo empleo legítimo "no era más que el procedimiento contra la insubordinación y la desobediencia", y que es defendible como la potestad conferida al Magistrado de sancionar en la $u r b$, los actos ilícitos mediante un sistema de medios aflictivos corporales y patrimoniales, principalmente la multa como pena, con la admisión de la provocatio ad populum como apelación ante el Tribunal del Jurado popular contra la condena impuesta por el Magistrado" (Mommsem, citado en Trillo, 2009. p. 29).

Agrega que así como el procedimiento penal era la realización de las leyes morales del Estado, "la coerción era la realización del poder supremo discrecional de este último, el imperium, sin el cual no hay obediencia posible de los ciudadanos, y por consecuencia, no es posible que exista la comunidad" (p. 30).

Así, las Quaestiones Perpetuae se relacionan históricamente con el crimen repetundarum. La quaestio de repetundis se castigó por primera vez en el año $171 \mathrm{~A}$. C. los abusos de poder cometidos por los Magistrados en las provincias de Hispania, acciones que motivo al Senado a ejercer las acciones pertinentes para nombrar un colegio de cinco recuperatores escogidos entre los mismos senadores para la representación y asistencia en el juicio, previendo de esta forma el abuso de poder causado por parte de los magistrados. 
A partir de la cuaestio repetendarum se fueron creando otros órganos de investigación y acusación, denominados por tal motivo quaestiones, las cuales representan el tránsito del proceso penal privado comicial al proceso penal público ante el Tribunal Popular del Jurado presidido por un Magistrado: La transformación del antiguo procedimiento penal de los comicios con el Magistrado en el posterior procedimiento por quaestiones no consistió, sustancialmente, en otra cosa que sustanciar los delitos públicos en la misma forma en que se hacía uso del procedimiento privado, pues, por una parte se concibió el juicio como una controversia jurídica entre la comunidad y el inculpado, y por otra, una vez que fue regulada la representación de la comunidad, el procedimiento por jurados se aproximó mucho al que usaban los Comicios, ya que el jurado único o el pequeño Tribunal de los recuperatores fue reemplazado por grandes colegios de jurados, y la presidencia de estos grandes colegios le fue encomendada a un Magistrado (Trillo, 2008, pág. 31).

Pese a lo expuesto el concepto de acusación resulta distante de lo que hoy se entiende por tal acto procesal, pero, en cambio, sí logró condensar de una u otra forma las fuentes para deducir un ejercicio de congruencia bastante desarrollada, no a la altura del proceso civil, pero si apropiado al esquema procesal penal.

- Cognitio extra ordinem: En este nuevo procedimiento el "Emperador tiene el más absoluto poder jurisdiccional; tiene potestad de avocar, reclamando el conocimiento de cualquier hecho delictivo, incluso el asumido por una quaestio concreta, sustrayendo el conocimiento de este hecho al Juez ordinario" (Trillo, 2008, pág. 37); su jurisdicción incluye la competencia para conocer en apelación de todas las sentencias pronunciadas tanto dentro como fuera de la península itálica por Magistrados y funcionarios subordinados a él, sin importar el caso litigioso.

Este procedimiento implicó la imperiosa decadencia del principio acusatorio, debido a que el juez que instruía producía la sentencia sin el control de un jurado, de los comicios o de los jueces diferentes. Tal modelo en el Derecho Penal, evidenciaba un cambio sustancial en la forma de procesar y, sin lugar a dudas, con ello una inminente desaparición de la congruencia como límite del poder punitivo de los magistrados. 
Entonces, de las deducciones que se pueden extraer de la historia, en cuanto al principio de congruencia en materia penal, se tiene que existen algunos claros ejemplos de su ejercicio, tal como los señalados en los libros 47 a 49 del Digesto que hacían referencia a las causa penales, y las referencias procesales apenas incorporan con detenimiento temas tales como la acusación - títulos II y XVI del libro 48 - y las competencias libro 49 .

Lo importante de esta referencia es que se distinguía la denuncia de la acusación, sin importar si era presentada por una persona privada. "La acusación es un acto formal de denuncia o atribución de un crimen a una persona determinada. Dicha denuncia tenía que ser vertida en un escrito recepcionado por el magistrado competente, en el cual se consignaban unos datos mínimamente necesarios" (Moya, 2012, pág. 48). Se interpreta que era una simple denuncia antes de erigirse en escrito de acusación, el cual una vez producido adquiría connotaciones semejantes a las de la fórmula del proceso civil.

Tan comprometedor era el escrito de acusación que debía caucionarse acerca de su veracidad. Y más aún, la misma caución se reclamaba para que el acusador la sostuviera hasta el día de la sentencia; prácticamente lo único que podía desvincular al acusador con su acusación era su muerte. De otro lado, "la tendencia acusatoria se hacía aún más visible en el sentido de que el acusador debía demostrar su acusación, tanto así que algunas personas no podían acusar como consecuencia de su pobreza" (Moya, 2012, pág. 48).

En suma, la acusación vinculaba en sus términos de manera grave y trascendental al acusador. De ahí que la importancia que adquiere respecto de la congruencia es la inquietud que en su momento planteó Marciano, en el sentido "de si el hecho de no poder demostrar la acusación conllevaba señalamiento de calumnia contra el denunciante y, con ello, la pena prevista en las leyes que en su momento fueron pronunciadas y que castigaba a los calumniadores" (Cuena, 1998, pág. 134). Así, no se tenían razones para deducir la atribución de facultades iura novit curia a los jueces penales en términos de congruencia.

Así, se puede establecer que la congruencia emerge como un esquema de creación social de la realidad, a través del Litis contestatio que forjaba una transformación de dimensiones significativas: lo que había sido hasta el momento una relación jurídica 
precedente, "perdía ónticamente su esencia o, lo que es igual, dejaba de ser en sí para surgir en cambio por obra de la construcción formularia del pretor, una nueva realidad consistente en una tensión que debía desatarse mediante la sentencia" (Moya, 2012, pág. 55).

La congruencia penal en su versión primigenia no fue apenas un asunto de coherencia interna del proceso, fue ante todo un modelo de control político sobre el acusador, con una clara fundamentación ideológica correspondiente con las características de responsabilidad que se acuño en el Derecho romano.

\section{Concepto}

De "latín congruentia, conveniencia, coherencia, relación lógica. En Derecho conformidad entre los pronunciamientos del fallo y las pretensiones de las partes formuladas en el juicio" (Diccionario de la lengua española, 2001, pág. 422).

La congruencia se significa también la "conformidad que debe existir entre la sentencia y la pretensión o pretensiones que constituyen el objeto del proceso, más la oposición y oposiciones en cuanto delimitan este objeto, teniendo en cuenta todos los elementos individualizadores de tal objeto: los sujetos que en él figuran, la materia sobre que recae y el título que jurídicamente lo perfila" (Guasp, 1961, pág. 567).

En tal sentido, existen tres clases de incongruencia: "cuando el fallo contiene más de lo pedido - positiva -, la que se da cuando en la sentencia se omite decidir sobre alguna de las pretensiones procesales - negativa $-\mathrm{y}$ las que se dan cuando las sentencias fallan sobre un objeto diferente al pretendido - mixta -" (Rioja, 2008, pág. 67).

"Las tres clases de incongruencia quedarían dentro de las expresiones: ultra citra y extra petita: más allá, menos y fuera de lo pedido" (D’onofrio, 1945, pág. 102).

Incurre en el vicio de extra petita el juez que resuelve a favor o contra personas que no son sujetos del proceso, cuando acuerda o niega cosa diferente de la demanda o cuando cambio la causa litigiosa. Por su parte, Chiovenda (1995) expresaba que los 
"jueces son muy inclinados a argumentar con hechos que las partes no han alegado, con el pretexto que resultan de los autos; temen quedar por debajo de su alta función si no ejercitan con absoluta independencia su ingenio sobre todo lo que se desprende de los autos (pág. 218).
"Si el juez se siente a disgusto encerrado en los cauces marcados por la volun- tad dominadora de las partes, al menos por una consideración práctica debe conformarse a este sometimiento, y es que las partes, son los mejores jueces de la propia defensa y que nadie mejor que ellas reconoce qué hechos deben alegar y cuáles no. La esfera de actividad del defensor y la del juez deben estar netamente separadas, ya que existe una verdadera incompatibilidad psicoló- gica entre la función de juzgar y la de buscar los elementos de defensa de las partes" (D’onofrio, 1945, pág. 102).

De lo expuesto, se predica que el juez no debe valerse de sus conocimientos privados para resolver la Litis, sino de lo probado y alegado en el desarrollo del proceso o litigio.

Desde otro punto de vista, Bernal (1995) expresa que el principio de congruencia es la exigencia de correlación entre acusación y sentencia, y que la sentencia debe tener como fundamento el recuento de lo investigado en el desarrollo del proceso cuyos aspectos son concretados en la acusación, la cual cumple la función fundamental de delimitar el objeto de la relación jurídica, "puesto que la sentencia como acto que concluye el proceso, debe proferirse en correspondencia con los hechos que motivaron la acusación y los imputados a quienes se formuló pliego de cargos” (pág. 15).

En este sentido, para comprender un poco más el concepto del principio de congruencia, es importante hacer alusión a los dos sistemas que lo desarrollan, el naturalista y el normativista.

El sistema naturalista se caracteriza por la correlación existente en el hecho investigado, sin importar la denominación jurídica que se le dé; razón por la cual el objeto identificador de la acción es el hecho y no un tipo penal configurado, y "ello supone que el traspaso por el Tribunal de un tipo a otro, en tanto y en cuanto permanezca 
inmutable el hecho, es algo factible y normal que deja a salvo el exigible correlato" (Vanegas V. , 2013, pág. 16).

En cuanto al sistema normativista que se desprende del naturalista, se establece que la base de este es el enfoque jurídico penal del hecho, pues sin este no cabe la identificación procesal del hecho. Por ende, "el hecho comprende un núcleo básico, sustancial, decisivo para su configuración y que deviene invariable a lo largo del procedimiento hasta su reflejo final en la resultancia sintética de la sentencia" (Vanegas V. , 2013, p. 16).Por consiguiente, los elementos accidentales que devienen del proceso logran atraer la atención de los jueces y las partes, sustentado en la norma penal que configura la parte formal del acto litigioso y lleva a la aceptación de la sentencia resolutoria; aspectos que reflejan características "como la inmutabilidad del hecho y la denominación jurídica que recibe, constituyen la adecuación típica contenida en pliego de cargo inmodificable y que solo puede ser cuestionada a través de la nulidad" (Vanegas V. , 2013, p. 16).

Entonces, al presentarse la solicitud de nulidad en el desarrollo de un proceso, basada en la imprecisión que privó el ejercicio de una adecuada defensa, es en donde entra a jugar el principio de congruencia, porque el ejercicio procesal de comienzo a fin debe ser congruente - imputación, intimación, contradicción, prueba, sentencia -, aspecto que lleva a afirmar que este principio es una expresión fundamental del derecho de defensa. De ahí que el derecho a defenderse recae en la posibilidad que tiene el sujeto de expresarse libremente sobre los hechos que se le imputan y las pruebas que sobre estos se presenten.

Sin embargo, hay quienes consideran, como Vélez (1986), que el principio de congruencia en materia penal recae exclusivamente sobre lo fáctico, demostrándose como indispensable la coincidencia o conveniencia entre el supuesto de hecho imputado y el contenido fáctico de la decisión. "Significa que la sentencia debe limitar su contenido fáctico al ámbito de la acusación y, en caso, con las legítimas ampliaciones que se denominan correlación entre acusación y sentencia” (p. 111).

Creus (1996) citado por Vanegas (2013) define que el proceso penal se rige por el principio de congruencia, los hechos por los que fue indagado el imputado son los que informan el contenido de los hechos que pueden ser objeto del auto 
de procesamiento; los comprendidos en este auto constituyen, a su vez, el límite fáctico del requerimiento de elevación a juicio, y son los hechos comprendidos en ese requerimiento (salvo excepciones taxativamente previstas por la ley) los que pueden ser objeto del debate y de la sentencia. Pero el principio de congruencia refiere a los "hechos" no a su calificación jurídica, por eso el tribunal podrá dar al hecho una calificación jurídica distinta a la contenida en el auto de remisión a juicio o en el requerimiento fiscal, aunque deba aplicar penas más graves o medidas de seguridad (Vanegas V. , 2013, p. 19).

Así, la congruencia es la compatibilidad o adecuación existente entre el hecho que impulsa el proceso y el resultado de la sentencia. Sin embargo, debe establecerse que la correlación entre acusación y sentencia no es comprendida como sinónimo de identidad o adecuación perfecta en toda su extensión. Al dictar sentencia, el juez debe adecuar el pronunciamiento al principio de congruencia, lo que constituye en realidad un componente lógico.

\section{EL PRINCIPIO DE CONGRUENCIA EN EL DERECHO PENAL COLOMBIANO}

El principio de congruencia, desde la regulación legal que rigió bajo la vigencia del Decreto 2700 (1991), se consagró en el artículo 442, pese a que dicha norma determinaba los requisitos formales que debían contenerse en la resolución de acusación. El mencionado artículo decía "3. La calificación jurídica provisional, con señalamiento del capitulo dentro del título correspondiente del Código Penal"(Decreto 2700, 1991, art. 442), indicando más adelante la necesidad de una "narración sucinta de los hechos investigados, con todas las circunstancias de modo, tiempo y lugar que los especifiquen" (Decreto 2700, 1991, art. 442),.

Concretamente en aquella oportunidad legislativa nada se dijo sobre la posibilidad de modificar o variar la calificación jurídica, pero así se entendió al hablarse en el numeral 3 del artículo en referencia de una "calificación jurídica provisional". A través de la Corte Constitucional se declaró la exequibilidad del artículo 442 del Decreto 2700 de 1991, en aquella oportunidad la Corte señaló: 
"El punto central de la argumentación planteada por el actor para pedir la inexequibilidad del vocablo impugnado, contenido en el artículo 442 del Código de Procedimiento Penal, consiste en que, según lo estima, si la Fiscalía, al culminar la investigación y al resolver, con base en ella, que debe proferirse resolución de acusación, efectúa una calificación jurídica apenas "provisional" acerca de delito y de las piezas procesales recaudadas, obstaculiza la defensa el sindicado. Este -según la demanda, se prepara teniendo presente lo expresado en la resolución de acusación, para defenderse de cierto cargos, dentro de unas determinadas circunstancias y bajo un inicial pronunciamiento de la administración de justicia en torno a los elementos que habrían de considerarse en la sentencia, pero, si resulta posteriormente sorprendido por la variación que el juez introduzca a la calificación inicial, le son modificados los presupuestos de los cuales partía y, por lo tanto, su defensa pierde vigor y fundamento, lo que implica, en criterio del demandante, una abierta vulneración del artículo 29 de la Carta Política" (Corte Constitucional Sentencia C - 491, 1996).

A juicio de la Corte, por el contrario, el derecho de defensa tiene su realización en el establecimiento y práctica de las condiciones objetivos y verificables que el proceso no se adelantará sin la participación del sindicado ni de suerte que se lo prive de acudir a lo necesario, dentro de las reglas de la ley, para hacer valer sus derechos.

Posteriormente, a partir de la entrada en vigencia de la Ley 600 de 2000, se establece en el artículo 338 que en la indagatoria se le interrogará al individuo sobre los hechos que originaron su vinculación y se le pondrá de presente la imputación jurídica provisional, con lo que se evidencian los primeros cimientos de la imputación en términos procesales. Más adelante, la Corte Suprema de Justicia, a través de la sentencia 18457 del 14 de febrero de 2002, señalo derroteros para la aplicación práctica de la variación de la calificación jurídica con fundamento en el Decreto 2700 de 1991.

Seguidamente con los diversos pronunciamientos de la Corte Constitucional, aseguró:

"Se establece que con relación a la imputación jurídica provisional, esta debe tener ese carácter dado la necesidad de respetar el debido proceso, toda vez que se protege 


\section{la presunción de inocencia, la cual solo se desvirtúa con la sentencia condenatoria"} (Corte Constitucional Sentencia C - 620, 2001).

De otro lado, el mismo fallo determina que ante su errónea calificación lo procedente es la declaratoria de Nulidad.

Ahora bien, en cuanto a las variaciones en la calificación jurídica provisional, el máximo Tribunal Constitucional determinó que debe hacerse "por un juez independiente e imparcial, que este en capacidad de variar la imputación, sin pronunciarse sobre la responsabilidad del procesado" (Narváez, 2012, pág. 12).

En suma, con motivo de las diversas discusiones que sobre el principio de congruencia se surtieron al interior de la Comisión Redactora Constitucional creada por el Acto Legislativo $\mathrm{N}^{\circ} 003$ de 2002, se resaltan posturas como la del comisionado Ramírez Bastidas citado por Narváez (2012) quien subrayó que:

"Desde el punto de vista de las garantías, parece adecuado establecer un momento en el cual se le diga al individuo por qué se le está procesando. Señaló que no se debe tratar de una información a fondo pero sí que le permita empezar a tomar las medidas para defenderse y no esperar a que se le descubran los cargos cuando se le convoque a juicio, indicó ser partidario de que se dé ese tipo de formalización de la investigación sin que se vuelva al antiguo proceso” (p. 13).

Con lo que se dan los cimientos de la imputación como audiencia, momento determinante para activar el derecho de defensa por parte de quien es indiciado y luego imputado. Así, el principio de congruencia se circunscribe a la imparcialidad del Juez como exigencia del juego limpio procesal.

"Quien juzga no puede ser parte, es una máxima del principio acusatorio, que algún autor se da en llamar imparcialidad, que implica siempre la existencia de dos partes parciales enfrentadas entre sí que acuden ante un tercero, que no es parte, titular de la función jurisdiccional" (Tobón, 2011, pág. 49).

Además, la aplicación del principio de congruencia en desarrollo de los procesos penales con tendencia acusatoria, e incluso en vigencia de la Ley 600 de 2000 resulta 
ser un tema complejo, que en muchas ocasiones se ve volcado a una incorrecta aplicación, concluyendo en sentencias absolutorias o declaratoria de innecesarias nulidades, sacrificando la eficiencia y eficacia de la administración de justicia.

Resulta entonces lógico que de la mano con la congruencia, se encuentre la variación de la calificación jurídica, entendida como la modificación de la adecuación típica (en tanto es provisional) en actos posteriores a la acusación, con lo cual acusación y variación conforman un solo cuerpo, una unión que una vez realizada debe respetarse y en tal virtud, se encuentra de igual forma cobijada por el principio de congruencia.

El principio de congruencia en el Sistema Penal Acusatorio en Colombia es relativamente nuevo, pues es a partir de la entrada en vigencia de la Ley 906 de 2004 que se comienza a debatir sobre el asunto. Aclarado lo anterior, el principio de congruencia en Colombia tiene rango constitucional debido a que es concebido como un factor fundamental para la eficacia y respeto del derecho al debido proceso y la defensa. Así, dentro del Sistema Penal Acusatorio colombiano, este principio se comprende como la relación existente entre la acusación que realiza la fiscalía y la sentencia que dicta el juez de conocimiento, con ocasión que la sentencia no sea consecuente con la acusación, esta sería violatoria del principio en comento y por ende vulneradora del debido proceso.

En este orden de ideas, y teniendo en cuenta lo expuesto en el concepto de los sistemas naturalista y normalista, se tiene que Colombia aplica un sistema mixto, debido a que la Fiscalía al momento de formular acusación debe tener en cuenta la determinación del hecho fáctico y la calificación jurídica que este pueda recibir.

Con lo anterior, se podría decir que el sistema dual o mixto de congruencia exige varios momentos (Vanegas, 2011, pág. 23):

- Identidad de los hechos hace relación a la conducta fáctica y a la conducta material, pues la primera debe ser típica, antijurídica y culpable para adecuarse a la segunda.

- Los hechos individualizados en la acusación hacen alusión a que la formulación de acusación que realiza la Fiscalía tiene como finalidad informar al acusado 
de los hechos y cargos de los que se le imputa responsabilidad, e igualmente es requisito constitucional que éste tenga la oportunidad de defenderse en el marco de un proceso justo.

- La modificación de los cargos es bastante polémica, puesto que en el sistema penal acusatorio los cargos solo pueden ser modificados por la Fiscalía en específicos momentos procesales, y cuando ocurre algún cambio es deber de los jueces, ministerio público y fiscales garantizar al procesado la posibilidad de defenderse de todos y cada uno de los cargos acusados, y más aún de los nuevos.

Por consiguiente, en la práctica judicial uno de los problemas más importantes que se presenta es el referente al respeto por el principio de congruencia y la posibilidad que el funcionario judicial varíe la calificación jurídica, al punto de ser extensa la jurisprudencia sobre el tema, por parte, de la Corte Constitucional y Corte Suprema de Justicia en su Sala de Casación Penal.

De ahí que, resulta importante el tema de la variación de la calificación jurídica, por cuanto actualmente no tiene regulación constitucional ni legal y su ámbito de aplicación es reglado por la jurisprudencia exclusivamente; razón por la cual se hace necesario analizar dicha regulación y aplicabilidad en la praxis judicial; de esta forma se hace posible la solución de casos concretos sin detrimento de los derechos de las partes e intervinientes en el proceso penal, y sobre todo en aras de la búsqueda de la justicia material.

\section{Conclusiones}

En el derecho penal colombiano, un hecho no se puede considerar como una simple enunciación genérica, abstracta o hipotética, sino que debe concretarse a una situación definida en el espacio, en el tiempo, en un lugar determinado, con cada uno de sus protagonistas, se pretende entonces de manera concreta comunicar un obrar específico; de esa forma quienes fungen como partes y quienes tienen la calidad de intervinientes en el proceso penal puedan ejercer de manera clara las facultades que la ley procesal penal establece y satisfacer de esa manera garantías o principios básicos, entre otros, por ejemplo, el debido proceso, publicidad, contradicción o defensa. 
Es por ello que se habla en desarrollo de la línea jurisprudencial que sobre el tema maneja la Corte Suprema de Justicia en su Sala de Casación Penal, de hechos con relevancia jurídico penal, razón por la cual dentro de la sistemática de la Ley 906 de 2004 lo importante es la comunicación de lo fáctico de manera inmodificable o invariable y la posterior adecuación de ello dentro del mundo jurídico, es decir, la norma adjetiva penal impone únicamente que el fiscal dé a conocer el eje central, lo importante, lo trascendente, lo necesario, lo esencial, y solo aquello que ofrezca el conocimiento requerido para preservar los derechos y garantías procesales y fundamentales, desde allí única y sólida por ende entonces la acusación ergo la congruencia.

Dentro de este contexto debe concretarse en el acto de comunicación denominado imputación, dado que se trata del único aspecto inmodificable en el proceso penal, toda vez que en los actos procesales subsiguientes no se pueden cambiar, mutar o modificar para agravar la situación jurídica, tiene que haber identidad del núcleo fáctico desde la imputación hasta la finalización del proceso; en tanto solo de beneficiar al imputado podrán ser objeto de mutación, jamás en sentido contrario o para derivar cargos diferentes o de mayor significado jurídico punible, o mudar sustancialmente la esencia de la conducta óptica comunicada, lo anterior conforme a los últimos pronunciamientos del órgano de cierre de la Justicia Ordinaria en lo penal.

Como no hacer mención a que del postulado congruencia y su mala, equivocada, indebida e irresponsable aplicación, puede devenir una condena que eventualmente tenga una privación de la libertad, y con ella las consecuencias propias de su ejecución que no solo deben ser vistas de forma jurídico penal, sino tal vez las más importantes de forma social, familiar e individual.

\section{Bibliografía}

Artiga, A. (2013). La argumentación jurídica de sentencias penales en el Salvador. (Tesis de grado en Maestría). San Salvador: Universidad de El Salvador - Facultad de Jurisprudencia y Ciencias Sociales.

Corte Constitucional Sentencia C - 491. (1996). Bogotá, D.C.

Corte Constitucional Sentencia C - 620. (2001). Bogotá, D.C. 
Corte Suprema de Justicia Sala de Casacion Penal. (2014). Radicado. 20134. Bogotá, D.C. .

Cuena, B. (1998). Sistema Jurídico y Derecho Romano. La idea de sistema jurídico y su proyección en la experiencia jurídica romana. Cantabria: Calima.

D’ onofrio, P. (1945). Lecciones de Derecho Procesal Civil: parte general. Traducción de José Becerra Bautista. México: Jus.

Decreto 2700. (1991). Código Penal. Colombia: Congreso de la República.

Diccionario de la lengua española. (2001). Real academía española (Vigésima segunda edición ed., Vol. I). Colombia: Quebecor World.

Grambra y Oriol. (2008). Lógica Aristotélica. Barcelona: Dykinson.

Guasp. (1961). Derecho Procesal Civil. Madrid: Instituto de Estudios Políticos.

Ley 600. (2000). Código Penal. Colombia: Congreso de la República.

Ley 906. (2004). Código de Procedimiento Penal. Colombia: Congreso de la República.

Martínez, A. (2012). La fundamentación de las sentencias definitivas dictadas en el proceso declarativo común por los Juzgados Civiles y Mercantiles: análisis del principio de congruencia. (Tesis de grado). San Salvador: Universidad de El Salvador - Facultad de Jurisprudencia y Ciencias Sociales .

Moya, V. (2012). El principio de congruencia en el Procedimiento Penal de la Ley 904 de 2004. Investigación sociojurídica. Colombia: La Universidad la Gran Colombia.

Narváez, F. (2012). Principio de congruencia en la imputación fáctica y jurídica . (Artículo de grado). Colombia: Universidad Militar Nueva Granada - Maestría en Derecho Procesal Penal.

Rioja, B. (2008). Ejecución anticipada de la sentencia en el Proceso Civil. (Tesis doctoral). Perú: Universidad San Martín de Porres.

Tobón, P. (2011). Principio de congruencia en el Sistema Penal de tendencia acusatoria, derecho de defensa Vs. Objeto litigioso provisional. Colombia: Universidad Nacional.

Trillo, N. (2008). Ministerio Fiscal: día cronía de una vinculación política. Saberes revista de estudios jurídicos, económicos y sociales, 6, 1 - 70 . 
Vanegas, A. (2011). El principio de congruencia. Según la Sala de Casación Penal de la Corte Suprema de Justicia en el marco del Sistema Penal Acusatorio colombiano 2005 - 2010. Pereira: Universidad Libre.

Vanegas, V. (2013). El principio de congruencia. (Tesis de Maestría). Medellín: Universidad EAFIT - Escuela de Derecho . 